\title{
Perencanaan Site Layout Facilities Berdasarkan Traveling Distance dan Safety Index pada Proyek Pembangunan Hotel The Alimar Surabaya
}

\author{
Angga Sukma Wijaya dan Yusroniya Eka Putri \\ Jurusan Teknik Sipil, Fakultas Teknik Sipil dan Perencanaan, Institut Teknologi Sepuluh Nopember (ITS) \\ Jl. Arief Rahman Hakim, Surabaya 60111 Indonesia \\ e-mail: iput@ce.its.ac.id
}

\begin{abstract}
Abstrak-Ruang gerak yang sempit akan sulit untuk menentukan penempatan site facilities. Dengan perencanaan site layout facilities yang dapat menghemat pemakaian ruang bangun, hal ini memerlukan kecermatan dalam penempatannya karena berpengaruh pada produktivitas kerja. Semakin besar area yang digunakan dalam penempatan site facilities maka perjalanan antar fasilitas juga semakin banyak memakan waktu. Pembuatan alternatif site layout perlu dilakukan agar memperoleh site facilities yang optimal. Pada penelitian ini dilakukan perencanaan site layout facilities dengan traveling distance dan safety index atau bisa disebut multi objectives function sebagai acuannya. Hasil yang di dapatkan adalah pada saat pekerjaan Sub Structure, site layout yang paling optimal adalah pada alternatif 665 yang mempunyai travelling distance dan safety index terendah dengan nilai TD sebesar 13246,18 m atau mengalami penurunan sebesar $3,30 \%$ dan nilai SI sebesar 1048 atau mengalami penurunan sebesar 5,76\% dari kondisi eksisting. Sedangkan Pada saat pekerjaan Upper Structure, site layout yang paling optimal adalah pada alternatif 122 yang mempunyai travelling distance dan safety index terendah dengan nilai TD sebesar 18741,6 $\mathrm{m}$ atau mengalami penurunan sebesar 5,15\% dan nilai SI sebesar 1072 atau mengalami penurunan sebesar $6,78 \%$ dari perencanaan awal.
\end{abstract}

Kata Kunci- equal, perencanaan, safety index, site layout facilities, traveling distance, unequal.

\section{PENDAHULUAN}

$\mathrm{P}$ ada setiap proyek konstruksi, hal yang terkait dengan pengerjaan dan biaya proyek umumnya sangat penting. Terdapat berbagai hal yang berpengaruh, salah satunya adalah dalam merencanakan tata letak lapangan (site layout). Terkait dengan tata letak tersebut terdapat fasilitas-fasilitas proyek (site facilities) yang letaknya disekitar pembangunan proyek dan bersifat sementara. Untuk menentukan tata letak site facilities memerlukan kecermatan dalam penempatannya karena hal tersebut berpengaruh pada produktivitas kerja. Semakin besar area yang digunakan dalam penempatan site facilities maka perjalanan antar fasilitas juga semakin banyak memakan waktu. Pembuatan alternatif site layout harus di lakukan agar memperoleh site facilities yang optimal.

Proyek pembangunan hotel The Alimar Surabaya, adalah proyek 7 lantai yang berada di Jl. Ir. Soekarno no. 134 Surabaya. Bangunan tersebut memiliki lantai semi basement dan desain bangunan yang arsitektural. Luas Tanah $=900$ $\mathrm{m}^{2}$ dengan $\mathrm{KDB}=650 \mathrm{~m}^{2}$ sedangkan $\mathrm{KLB}=650 \mathrm{~m}^{2} \times 7$ lantai $=4550 \mathrm{~m}^{2}$. Bangunan tersebut berhimpitan langsung dengan rumah warga. Dengan ruang gerak yang sempit akan sulit untuk menentukan penempatan site facilities. Tentu saja menentukan site layout juga akan semakin kompleks. Dengan perencanaan site layout facilities, diharapkan dapat menghemat pemakaian ruang bangun.

Dalam pengelompokannya optimasi site layout dikerjakan dengan dua acuan yaitu traveingl distance (TD) dan safety index (SI). Dengan dua acuan tersebut maka pengerjaan optimasi ini dapat disebut dengan metode Multi Objectives Function.

Rencana peletakan bangunan-bangunan pembantu yang bersifat temporal yang diperlukan sebagai sarana pendukung untuk pelaksanaan pekerjaan. Oleh karena sifatnya yang temporal maka pada akhirnya bangunan ini harus dibongkar sehingga pemilihan jenis material disesuaikan dengan keadaan dan kondisi lokasi. Tujuan pembuatan rencana tersebut adalah mengatur letak bangunan-bangunan pembantu sedemikian rupa sehingga pelaksanaan pekerjaan dapat berjalan dengan efisien, lancar, aman dan sesuai rencana kerja yang disusun (Ervianto, 2002) [1]. Fasilitas site konstruksi direpresentasikan menggunakan bentuk persegi 2D dan dikategorikan kedalam 3 tipe: fasilitas tetap (fixed), yang tidak dapat bergerak (stationary) dan yang dapat bergerak (moveable) (El Rayes dan Said, 2009) [3]. Hal-hal yang perlu diperhatikan dalam perencanaan layout fasilitas dan sarana yang diperlukan untuk pelaksanaan suatu proyek dapat dilihat pada buku terbitan (PT. PP (Persero), 2003) [2]. Lokasi proyek merupakan salah satu lingkungan kerja yang mengandung risiko cukup besar. Tim manajemen sebagai pihak yang bertanggung jawab selama proses pembangunan berlangsung harus mendukung dan mengupayakan program-program yang dapat menjamin agar tidak terjadi/meminimalkan kecelakaan kerja atau tindakantindakan pencegahannya (Ervianto, 2002) [1].

\section{METODOLOGI}

\section{A. Tahap Penelitian}

Dalam melakukan sebuah penelitian diperlukan langkah penelitian yang tersusun secara baik dan tepat. Tahapan yang disusun harus bisa mempermudah maupun mempercepat proses pencarian data hingga pengolahan data. Penelitian ini merupakan studi kasus untuk perencanaan site layout facilities pada proyek pembangunan hotel The Alimar Surabaya. Penilitian ini menggunakan acuan traveling distance dan safety index. Bentuk site layout facilities yang optimum adalah site layout yang memiliki nilai traveling distance dan safety index minimum. 
Pada penelitian ini secara garis besar akan di lakukan dua kali perencanaan site layout yaitu pada kondisi sub structure dan upper structure. Untuk pemodelan juga di bagi menjadi dua yaitu pemodelan equal dan unequal site layout.

Diagram alir penelitian dapat dilihat pada gambar 3.1

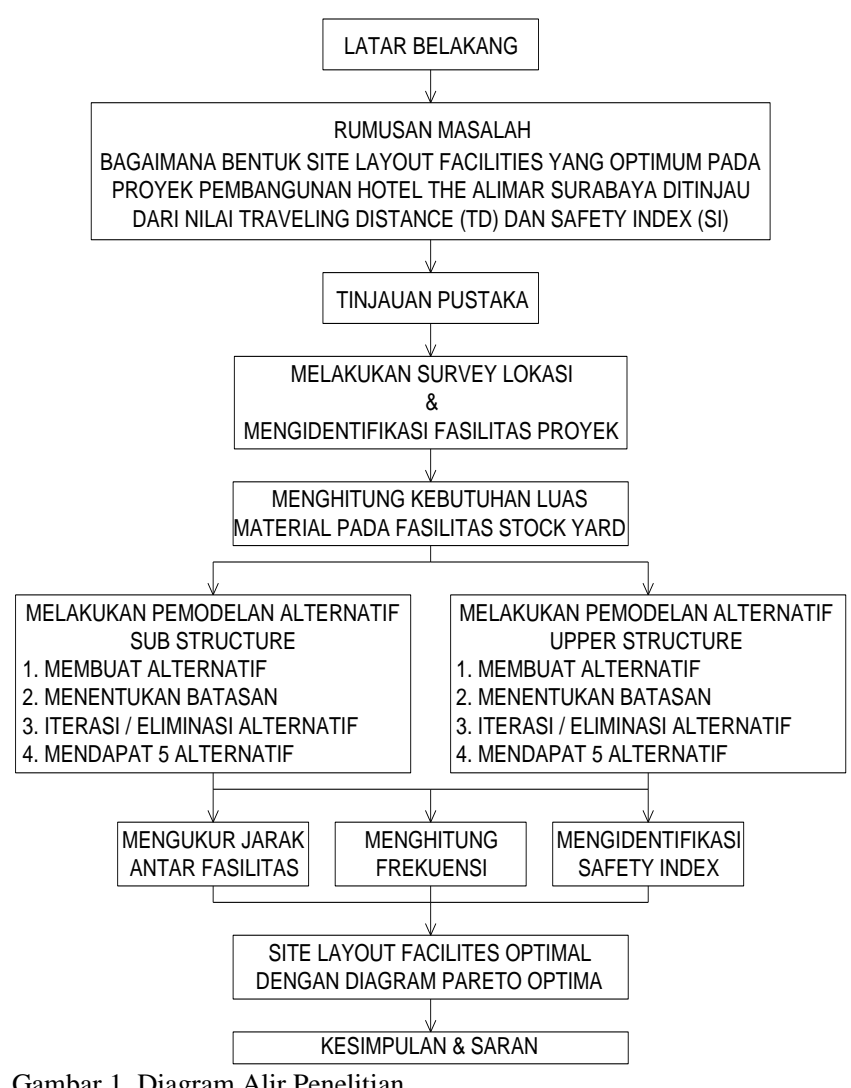

Penjelasan lengkap tentang Metodologi dapat dilihat pada buku Tugas Akhir penulis.

\section{HASIL DAN PEMBAHASAN}

\section{A. Survey dan Pengumpulan Data}

Survey dan pengumpulan data dilakukan langsung di lapangan pada proyek pembangunan hotel The Alimar Surabaya. Proyek ini merupakan bangunan berbentuk artistik yang terdiri dari 7 lantai dengan semi basement pada lantai paling bawah dan atap baja pada struktur bangunan atas. Proyek ini mempunyai fasilitas-fasilitas penunjang untuk pelaksanaan pembangunannya. Lahan terbatas pada proyek tersebut membutuhkan penempatan-penempatan fasilitas yang optimal. Survey dilakukan untuk mengumpulkan data tata letak fasilitas, luasan tiap fasilitas, jarak antar fasilitas, frekuensi perpindahan antar fasilitas dan indentifikasi safety index. Survey lokasi menyasar pada lingkup proyek tempat pembangunan saja.

Dari hasil survey yang dilakukan melalui proses pengamatan di lapangan serta wawancara dengan Project Manager, Site Engineer Manager dan logistik selaku kontraktor pelaksana, penyediaan dan perencanaaan fasilitas dibagi menjadi dua tahap. Tahap pertama adalah site layout facilities pada pekerjaan sub structure dan tahap kedua pada saat pekerjaan upper structure. Selain itu dari hasil survey pada proyek tersebut juga didapatkan data-data berupa gambar site layout, jenis fasilitas dan luasan fasilitas.

Gambar perencanaan tata letak fasilitas berupa data gambar site layout perencanaan awal proyek The Alimar Surabaya dapat dilihat pada gambar 4.1 berikut.

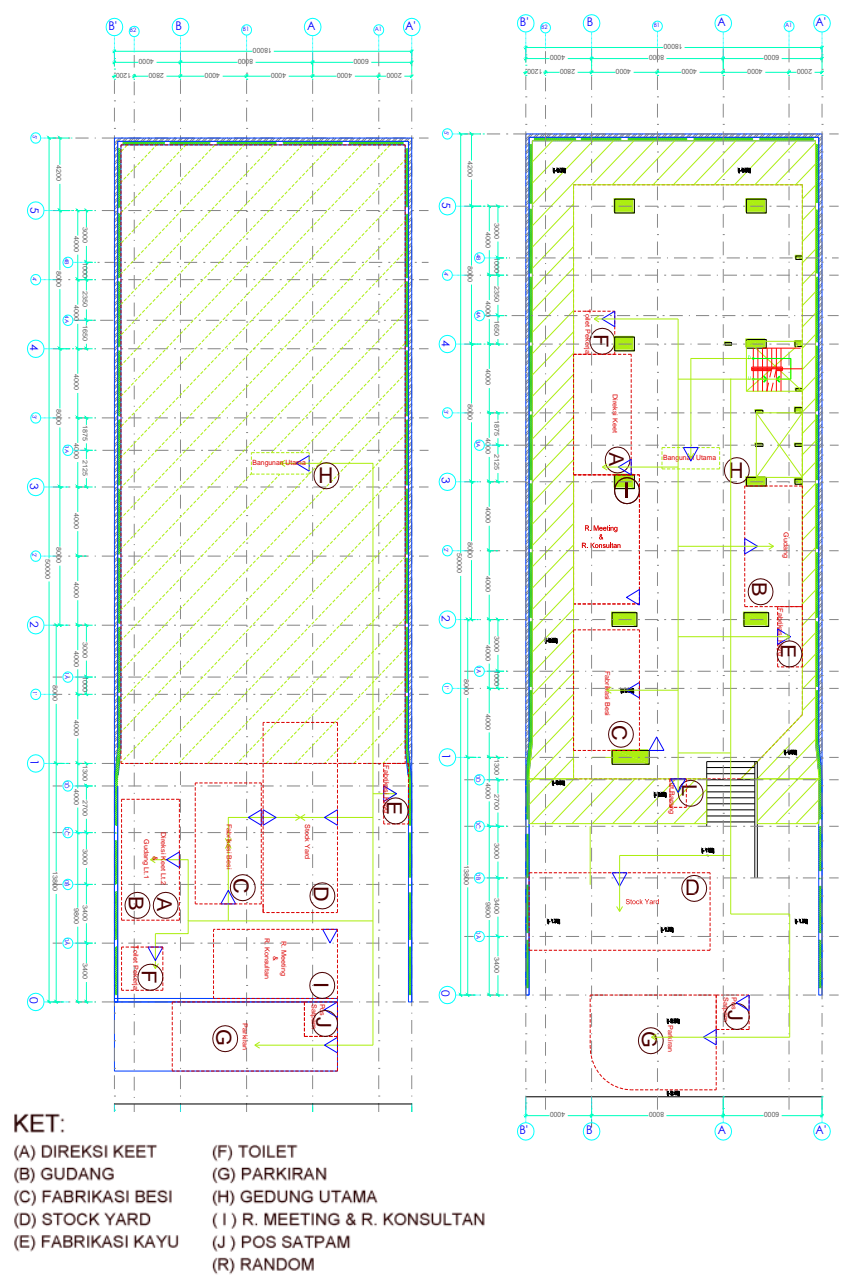

Gambar 2. Site Layout Perencanaan awal

Jarak antar fasilitas didapatkan dari hasil pengukuran lapangan maupun pada gambar kerja yang diberikan oleh pihak kontraktor. Contoh hasil pengukuran jarak antar fasilitas pada tahap pekerjaan sub structure dapat dilihat pada tabel 1 .

Table 1.

Contoh Hasi Pengukuran Jarak Antar Fasilitas Pekerjaan Sub Structure

\begin{tabular}{lrrrrrrrr}
\hline $\begin{array}{l}\text { Jarak } \\
\text { (m) }\end{array}$ & A & B & C & D & E & F & G & H \\
\hline A & 0 & 9,56 & 17,7 & 32,4 & 30,7 & 15,5 & 36,3 & 55,7 \\
& & & 4 & & 7 & 7 & 5 & \\
B & 9,56 & 0 & 12,7 & 27,4 & 25,7 & 10,5 & 31,3 & 50,7 \\
& & & 4 & & 7 & 7 & 5 & \\
C & 17,7 & 12,7 & 0 & 5,86 & 22,0 & 11,6 & 27,5 & 46,9 \\
& 4 & 4 & & & 1 & 6 & 8 & 4 \\
D & 32,4 & 27,4 & 5,86 & 0 & 7,18 & 26,3 & 24,7 & 32,1 \\
& & & & & & 2 & 2 & 1 \\
E & 30,7 & 25,7 & 22,0 & 7,18 & 0 & 24,7 & 23,1 & 27,7 \\
& 7 & 7 & 1 & & & & & 3 \\
F & 15,5 & 10,5 & 11,6 & 26,3 & 24,7 & 0 & 30,2 & 49,6 \\
& 7 & 7 & 6 & 2 & & & 7 & 2 \\
G & 36,3 & 31,3 & 27,5 & 24,7 & 23,1 & 30,2 & 0 & 48,0 \\
& 5 & 5 & 8 & 2 & & 7 & & 3 \\
H & 55,7 & 50,7 & 46,9 & 32,1 & 27,7 & 49,6 & 48,0 & 0 \\
& & & 4 & 1 & 3 & 2 & 3 & \\
\hline \hline
\end{tabular}


Frekuensi perjalanan pekerja antar fasilitas didapatkan dari hasil pengamatan di lapangan selama jam kerja normal dan wawancara dengan Site Engineer Manager. Frekuensi perpindahan pekerja antar fasilitas dapat dilihat pada tabel 2 berikut.

Table 2.

Frekuensi Perpindahan Pekerja Antar Fasilitas

\begin{tabular}{llrrrrrrr}
\hline \hline Frekuensi & A & B & \multicolumn{1}{l}{ C } & \multicolumn{1}{c}{ D } & E & F & \multicolumn{1}{c}{ G } & \multicolumn{1}{c}{ H } \\
\hline A & 0 & 1 & 1 & 0 & 0 & 0 & 0 & 3 \\
B & 1 & 0 & 5 & 10 & 6 & 8 & 15 & 25 \\
C & 1 & 5 & 0 & 6 & 1 & 1 & 2 & 23 \\
D & 0 & 10 & 6 & 0 & 15 & 8 & 17 & 28 \\
E & 0 & 6 & 1 & 15 & 0 & 0 & 3 & 21 \\
F & 0 & 8 & 1 & 8 & 0 & 0 & 20 & 1 \\
G & 0 & 15 & 2 & 17 & 3 & 20 & 0 & 4 \\
H & 3 & 25 & 23 & 28 & 21 & 1 & 4 & 0 \\
\hline \hline
\end{tabular}

Identifikasi tingkat bahaya dilakukan dengan cara wawancara untuk memperoleh data mengenai tingkat keamanan dan kemungkinan terjadinya kecelakaan kerja. Contoh hasil penentuan niali safety index dapat dilihat pada tabel 3 berikut.

Tabel 3. Contoh Hasil Penentuan Nilai Safety Index Antar Fasilitas

\begin{tabular}{lllllllll}
\hline \hline Safety & A & B & C & D & E & F & G & H \\
\hline A & 0 & 3 & 3 & 3 & 3 & 3 & 3 & 3 \\
B & 3 & 0 & 3 & 3 & 3 & 3 & 3 & 3 \\
C & 3 & 3 & 0 & 3 & 3 & 3 & 3 & 3 \\
D & 3 & 3 & 3 & 0 & 2 & 3 & 2 & 2 \\
E & 3 & 3 & 3 & 2 & 0 & 3 & 1 & 1 \\
F & 3 & 3 & 3 & 3 & 3 & 0 & 3 & 3 \\
G & 3 & 3 & 3 & 2 & 1 & 3 & 0 & 1 \\
H & 3 & 3 & 3 & 2 & 1 & 3 & 1 & 0 \\
\hline \hline
\end{tabular}

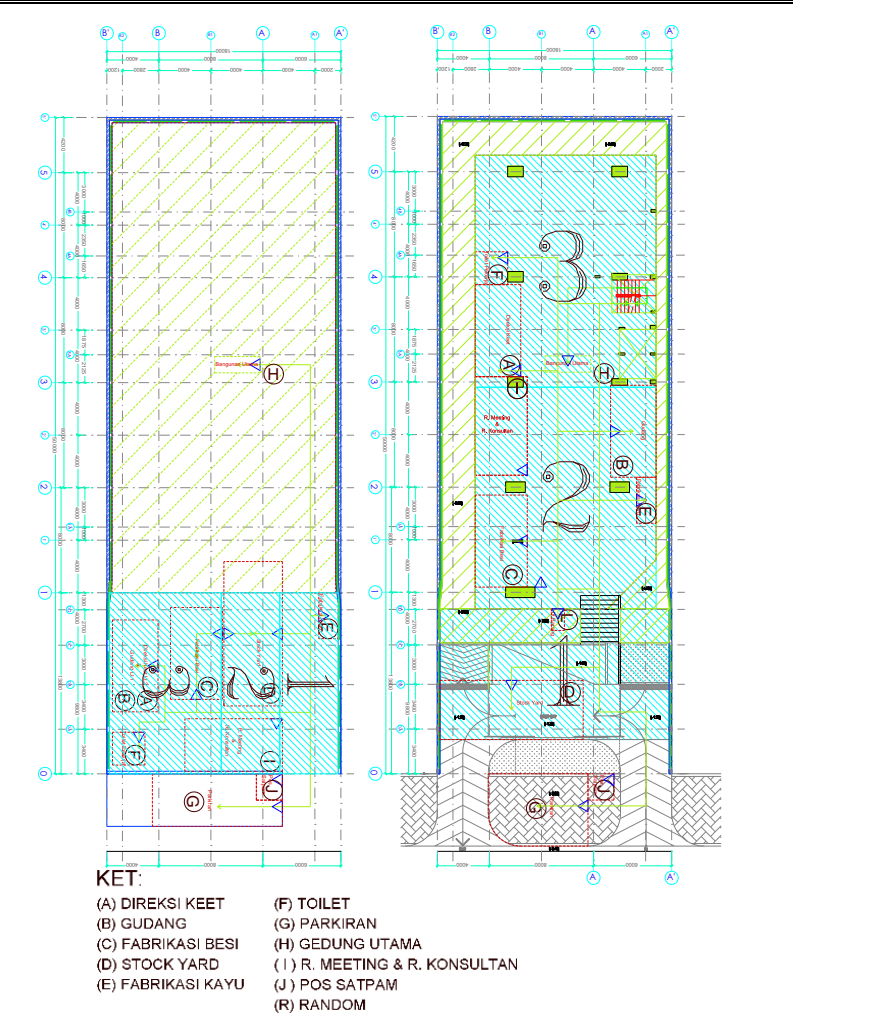

Gambar 3. Pembagian zona safety index Sub Structure dan Upper Structure

\section{B. Perhitungan Optimasi}

Sebelum masuk ke perhitungan traveling distance dan safety index terlebih dahulu menentukan alternatif apa yang di pakai untuk di jadikan bentuk site layout yang kemudian di lakukan optimasi. Menentukan alternatif yang dipakai dengan cara iterasi dengan batasan-batasan perpindahan yang dibuat.

Dari 720 kemungkinan atau alternatif pertukaran antar dua fasilitas yang di acak dengan menggunakan cara permutasi, dipilih 5 alternatif yang sesuai dengan batasan-batasan perpindahan fasilitas yang ada

Analisa perencanaan site layout facilities ini menggunakan metode Multi Objectives Function. Metode tersebut merupakan istilah dari acuan variable optimasi yang lebih dari satu variable. Variable yang di pakai adalah Traveling Distance dan Safety Index.

\section{Traveling Distance (TD) \\ $\sum_{i, j=1}^{n} d_{i j} \times f_{i j}$}

Keterangan:

$\mathrm{TD}=$ hubungan antara jarak dengan frekuensi perpindahan antar fasilitas

$\mathrm{d} \quad=$ jarak antar fasilitas

$\mathrm{f} \quad=$ frekuensi perpindahan antar fasilitas

$\mathrm{n} \quad$ = jumlah fasilitas

Traveling distance di ukur sesuai jarak x,y,z pada lapangan. Traveling Distance juga mengacu pada alur (path) yang setiap alurnya akan melalui nilai safety index yang berbeda-beda tergantung dari dampak bahaya yang di identifikasi dan dikelompokkan dalam tabel.

$\sum_{i, j=1}^{\substack{n \\ n}} S_{i j} \times f_{i j}$

Keterangan:

SI = hubungan antara tingkat keamanan frekuensi perpindahan antar fasilitas

$\mathrm{s} \quad=$ tingkat keamanan

$\mathrm{f} \quad=$ frekuensi perpindahan antar fasilitas

$\mathrm{n} \quad=$ jumlah fasilitas

Berikut merupakan hasil perhitungan traveling distance dan safety index tersebut.

- Traveling distance dan safety index fase pekerjaan sub structure

1) Alternatif 1 (perencanaan awal)

Permutasi yang dipakai sebagai acuan utama adalah ABCDEF.

Setelah dilakukan perhitungan terhadap alternatif 1 , maka didapatkan nilai TD sebesar 13697,98 m. Dari perhitungan SI alternatif 1 didapatkan nilai SI sebesar 1112.

\section{2) Alternatif 719}

Alternatif 719 mengambil pendekatan permutasi FEDCAB. 
Setelah dilakukan perhitungan terhadap alternatif 719 , maka didapatkan nilai TD sebesar 14645,62 m. Apabila dibandingkan dengan TD alternatif 1 maka alternatif ini mengalami kenaikan nilai TD sebesar 6,92\%. Dari perhitungan SI alternatif 719 didapatkan nilai SI sebesar 1238. Apabila dibandingkan dengan SI alternatif 1 maka alternatif ini mengalami kenaikan nilai SI sebesar 11,33\%.

\section{3) Alternatif 7}

Alternatif 7 mengambil pendekatan permutasi ABDCEF.

Setelah dilakukan perhitungan terhadap alternatif 7, maka didapatkan nilai TD sebesar 14286,2 m. Apabila dibandingkan dengan TD alternatif 1 maka alternatif ini mengalami kenaikan nilai TD sebesar 4,30\%. Dari perhitungan SI alternatif 7 didapatkan nilai SI sebesar 1228. Apabila dibandingkan dengan SI alternatif 1 maka alternatif ini mengalami kenaikan nilai SI sebesar 10,43\%.

\section{4) Alternatif 689}

Alternatif 689 mengambil pendekatan permutasi FDCEAB.Setelah dilakukan perhitungan terhadap alternatif 689, maka didapatkan nilai TD sebesar 13380,66 m. Apabila dibandingkan dengan TD alternatif 1 maka alternatif ini mengalami penurunan nilai TD sebesar 2,32\%. Dari perhitungan SI alternatif 689 didapatkan nilai SI sebesar 1230. Apabila dibandingkan dengan SI alternatif 1 maka alternatif ini mengalami kenaikan nilai SI sebesar 10,61\%.

\section{5) Alternatif 665}

Alternatif 665 mengambil pendekatan permutasi FCDEAB.Setelah dilakukan perhitungan terhadap alternatif 665 , maka didapatkan nilai TD sebesar 13246,18 m. Apabila dibandingkan dengan TD alternatif 1 maka alternatif ini mengalami penurunan nilai TD sebesar 3,30\%. Dari perhitungan SI alternatif 665 didapatkan nilai SI sebesar 1048. Apabila dibandingkan dengan SI alternatif 1 maka alternatif ini mengalami penurunan nilai SI sebesar 5,76\%.

\section{DIAGRAM HUBUNGAN TD\&SI}

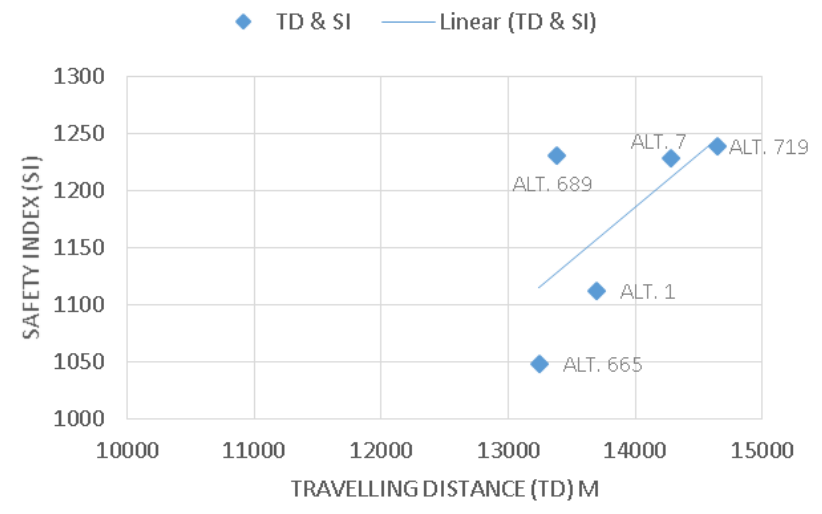

Gambar 4. Diagram Pareto Optima Site Layout Pada Saat Pekerjaan Sub Structure

Dari gambar 4 di atas, dapat dilihat bahwa terdapat salah satu alternatif yang mendekati titik 0. Titik alternatif yang paling mendekati titik 0 adalah yang paling optimum karena mempunyai nilai TD dan SI yang minimum. Titik alternatif yang mendekati titik 0 adalah alternatif 665 . Maka alternatif 665 dapat di sebut memiliki nilai TD dan SI paling minimum dari fasilitas-fasilitas lain yang dipilih. Sehingga alternatif 665 merupakan bentuk site layout yang optimum pada site layout pekerjaan sub structure ini. Gambar site layout optimum dapat dilihat pada gambar 5 berikut.

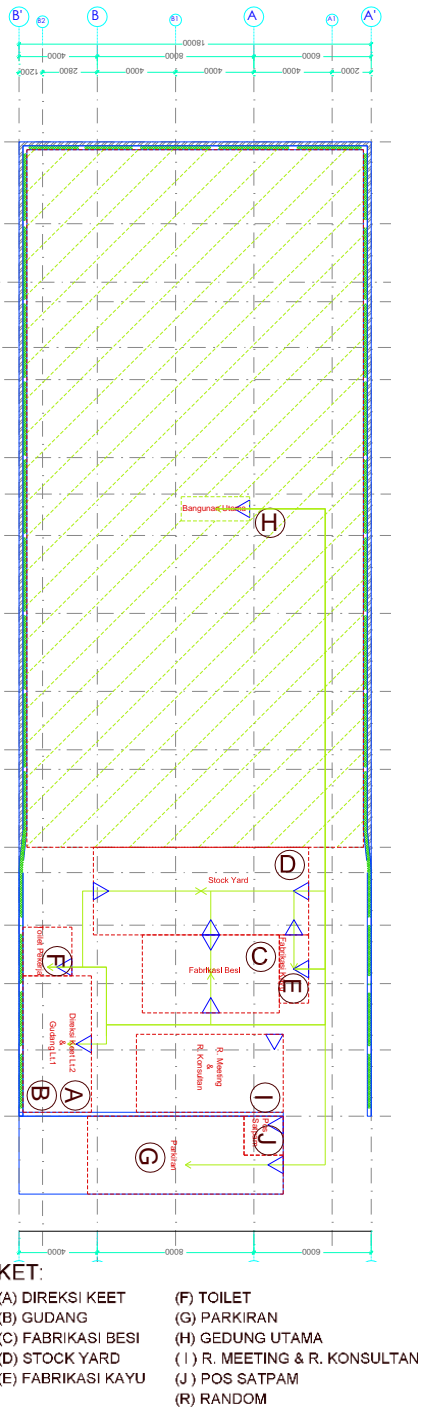

Gambar 5 Pemodelan Site Layout Alternatif 665

Traveling distance dan safety index fase pekerjaan upper structure

6) Alternatif 1

Permutasi yang dipakai sebagai acuan utama adalah ABCDEF.Setelah dilakukan perhitungan terhadap alternatif 1, maka didapatkan nilai TD sebesar 19759,44 m. Dari perhitungan SI alternatif 1 didapatkan nilai SI site layout sebesar 1150 .

\section{7) Alternatif 634}

Alternatif 634 mengambil pendekatan permutasi FBCDEA.Setelah dilakukan perhitungan terhadap alternatif 634, maka didapatkan nilai TD sebesar 19339,84 m. Apabila dibandingkan dengan TD alternatif 1 maka alternatif ini mengalami penurunan nilai TD sebesar 2,12\%. Dari perhitungan SI alternatif 634 didapatkan nilai SI site layout sebesar 1150. Apabila dibandingkan dengan SI alternatif 1 maka alternatif ini mengalami penurunan nilai SI sebesar $0 \%$. 


\section{8) Alternatif 122}

Alternatif 122 mengambil pendekatan permutasi BACDFE.Setelah dilakukan perhitungan terhadap alternatif 122, maka didapatkan nilai TD sebesar 18741,6 m. Apabila dibandingkan dengan TD alternatif 1 maka alternatif ini mengalami penurunan nilai TD sebesar 5,15\%. Dari perhitungan SI alternatif 112 didapatkan nilai SI site layout sebesar 1072. Apabila dibandingkan dengan SI alternatif 1 maka alternatif ini mengalami penurunan nilai SI sebesar $6,78 \%$.

\section{9) Alternatif 652}

Alternatif 652 mengambil pendekatan permutasi FCADEB.Setelah dilakukan perhitungan terhadap alternatif 652, maka didapatkan nilai TD sebesar 19681,8 m. Apabila dibandingkan dengan TD alternatif 1 maka alternatif ini mengalami penurunan nilai TD sebesar 0,39\%. Dari perhitungan SI alternatif 652 didapatkan nilai SI site layout sebesar 1162. Apabila dibandingkan dengan SI alternatif 1 maka alternatif ini mengalami kenaikan nilai SI sebesar $1,04 \%$.

\section{0) Alternatif 672}

Alternatif 672 mengambil pendekatan permutasi FCEDBA.Setelah dilakukan perhitungan terhadap alternatif 672, maka didapatkan nilai TD sebesar 20011,16 m. Apabila dibandingkan dengan TD alternatif 1 maka alternatif ini mengalami kenaikan nilai TD sebesar 1,27\%. Dari perhitungan SI alternatif 672 didapatkan nilai SI site layout sebesar 1146. Apabila dibandingkan dengan SI alternatif 1 maka alternatif ini mengalami penurunan nilai SI sebesar $0,35 \%$.

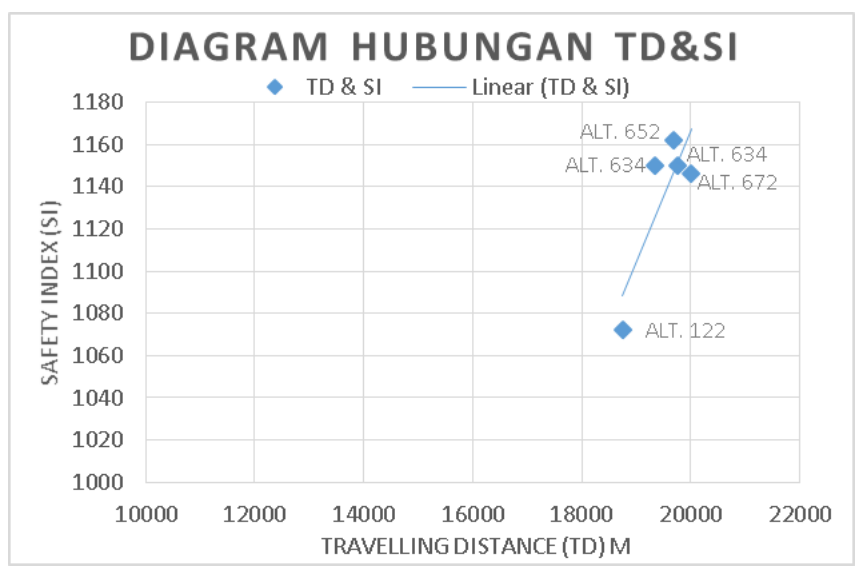

Gambar 6. Diagram Pareto Optima Site Layout Pada Saat Pekerjaan Upper Structure

Dari gambar 6 di atas, dapat dilihat bahwa terdapat salah satu alternatif yang mendekati titik 0. Titik alternatif yang paling mendekati titik 0 adalah yang paling optimum karena mempunya nilai TD dan SI yang minimum. Titik alternatif yang mendekati titik 0 adalah alternatif 122 . Maka alternatif 122 dapat di sebut memiliki nilai TD dan SI paling minimum dari fasilitas-fasilitas lain yang dipilih. Sehingga alternatif 122 merupakan bentuk site layout yang optimum pada site layout pekerjaan upper structure ini. Gambar site layout optimum dapat dilihat pada gambar 7 berikut.

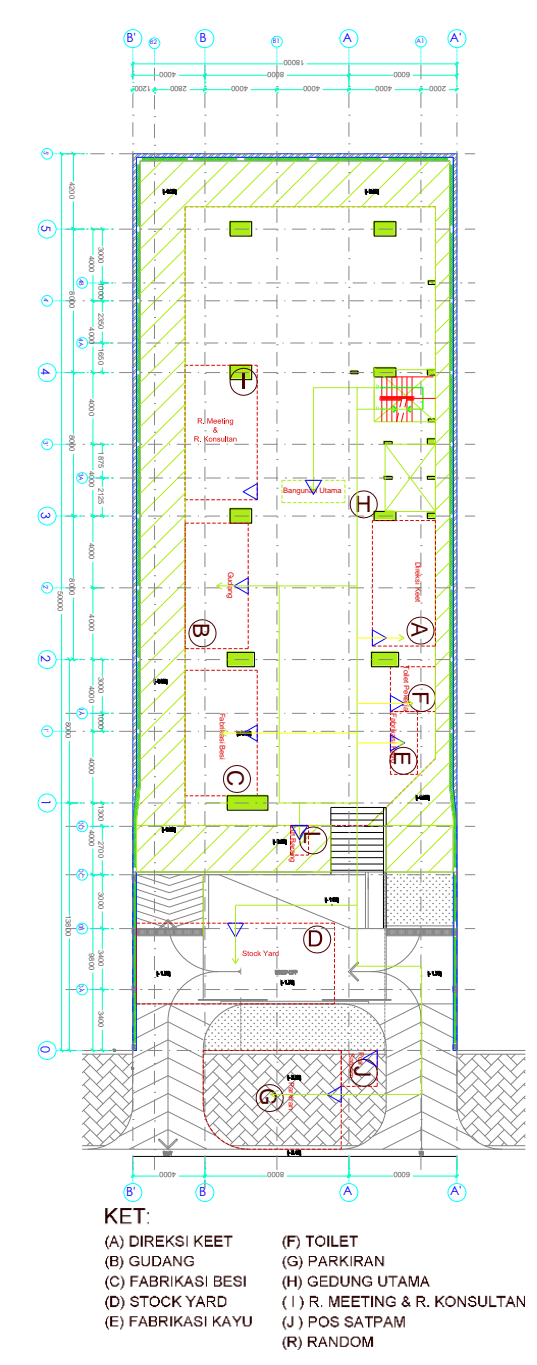

Gambar 7. Permodelan Site Layout Alternatif 122

\section{KESIMPULAN/RINGKASAN}

Berdasarkan hasil analisa yang telah dilakukan terhadap perhitungan optimasi site layout proyek pembangunan gedung hotel The Alimar Surabaya, diperoleh tata letak site layout facilities yang paling optimal.

Pada saat pekerjaan Sub Structure, site layout yang paling optimal adalah pada alternatif 665 yang mempunyai travelling distance dan safety index terendah dengan nilai TD sebesar 13246,18 $\mathrm{m}$ atau mengalami penurunan sebesar 3,30\% dan nilai SI sebesar 1048 atau mengalami penurunan sebesar $5,76 \%$ dari kondisi eksisting.

Sedangkan Pada saat pekerjaan Upper Structure, site layout yang paling optimal adalah pada alternatif 122 yang mempunyai travelling distance dan safety index terendah dengan nilai TD sebesar 18741,6 $\mathrm{m}$ atau mengalami penurunan sebesar $5,15 \%$ dan nilai SI sebesar 1072 atau mengalami penurunan sebesar $6,78 \%$ dari perencanaan awal.

\section{DAFTAR PUSTAKA}

[1] Ervianto, Wulfram I. 2002. Manajemen Proyek Konstruksi Edisi Revisi. Yogyakarta: Penerbit ANDI.

[2] PT. PP (Persero). 2003. Buku Referensi Untuk Kontraktor Bangunan Gedung dan Sipil. Jakarta: PT. PP (Persero).

[3] Rayes, El dan Said. 2009. Dynamic Site Layout Planning Using Approximate Dynamic Programming. 
[4] Wijaya, Angga Sukma. 2016. Perencanaan Site Layout Facilities Berdasarkan Traveling Distance dan Safety Index Pada Proyek pembangunan Hotel The Alimar Surabaya. Belum dipublikasikan 